\title{
Direct Shear Test: Normal and Tangential Stresses Evaluation According to Constant and Variable Shearing Area
}

\author{
Šarūnas Skuodis ${ }^{1}$, Arnoldas Norkus $^{2}$ \\ Geotechnical Engineering Department, Faculty of Civil Engineering, \\ Vilnius Gediminas Technical University, Vilnius, Lithuania \\ E-mails: ${ }^{1}$ sarunas.skuodis@vgtu.lt (correspondingauthor); ${ }^{2}$ arnoldas.norkus@vgtu.lt
}

\begin{abstract}
Investigations of soil shear strength properties for Baltic Sea shore sand along Klaipeda city is presented. Investigated sand angle of internal friction $(\varphi)$ and cohesion $(c)$ is determined via two different direct shear tests procedures. First procedure is standard and ordinary in geotechnical practice, when direct shear test is provided using constant shearing area. Second test procedure is different because shearing area according to horizontal displacement each test second is recalculated and reducing during horizontal movement. According to these two different testing procedures provided comparison of normal and tangential stresses.
\end{abstract}

Keywords: variable shearing area, direct shear test, normal stress, tangential stress, angle of internal friction, peak shearing strength, residual shearing strength.

Conference topic: Soil and rock investigation.

\section{Introduction}

The decision whether to use peak or residual shear strengths (Fig. 1) for a stability analysis must be made in the context of a specific design situation. In general, if there are potential construction, operation, or design conditions that might cause relative displacement between layers, then a post-peak or residual shear strength for the layer having the lowest peak strength is appropriate.

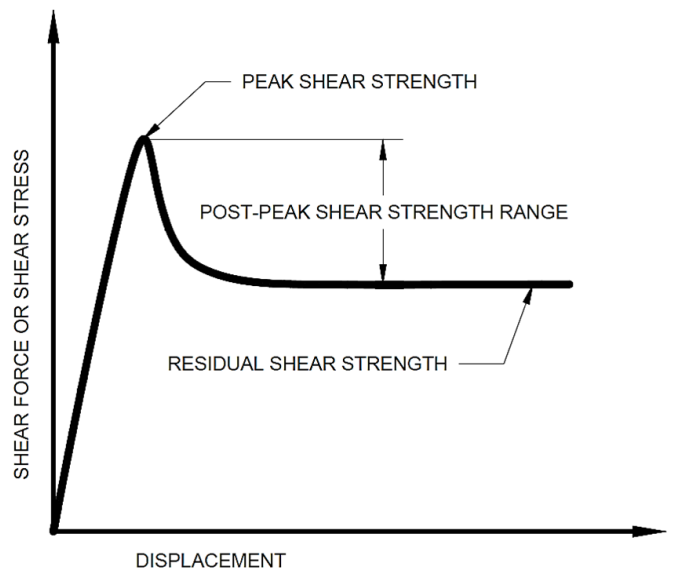

Fig. 1. Example graph of shear force or shear stress versus horizontal displacement (Thiel 2001)

Knowing, that shearing strength parameters depends on normal and tangential stress values (Khalilmoghadam et al. 2009; Havaee et al. 2015; Kimura et al. 2015; Wang et al. 2015) it was made a decision to evaluate variable shearing area (Naranjo et al. 2014; Skuodis, Tamošiūnas 2014; Taheri et al. 2015; Takano et al. 2014) during direct shear test.

\section{Methodology of direct shear test}

For investigations it was used sand from the North part of Klaipeda city in Giruliai at the Baltic Sea coast. The average density of particles $\left(\rho_{s}\right)$ varies from 2.65 to $2.67 \mathrm{~g} / \mathrm{cm}^{3}$. Sample density $(\rho)$ varies from 1.49 to $1.51 \mathrm{~g} / \mathrm{cm}^{3}$. Sand mineralogical composition consists basically of dominating ingredients, namely: $\sim 85 \%$ silica and $\sim 6 \%$ sunstone with remaining contribution of carbonate, mica and other minerals. Uniformity coefficient $C_{U}=1.47$, coefficient of curvature $C_{C}=0.93$ was obtained for investigated sand.

Used direct shear test is standard (Lane, Vanapalli 2002). Main difference of new testing methodology from standard one - recalculation of normal and tangential stress during direct shear test according to horizontal shearing ring movement $u$ (Fig. 2).

Standard direct shear test procedure is runned according to these steps: a) vertical stress loading up to chosen maximum stress and keeping constant vertical stress all testing procedure; $b$ ) establishment of horizontal bottom shearing ring movement with loading ramp $0.50 \mathrm{~mm} / \mathrm{min}$ up to maximum load $9.00 \mathrm{~mm}$ (Skuodis 2015).

Improved testing procedure is same as the standard one except the fact, that during horizontal movement each second is recalculated vertical and tangential stresses according to variable shearing area (Nguyen 2015).

In this case it is evaluated actual vertical and tangential stresses during testing. Variable shearing area is obtained by (1) formulae.

$$
\begin{aligned}
& A=2 \cdot\left[\frac{(d \cdot 0.5)^{2} \cdot \pi}{360^{0}} \cdot a \cos \left(\frac{u}{d}\right)\right]- \\
& {\left[\left(0.25 \cdot u \cdot \sin \left(a \cos \left(\frac{u}{d}\right)\right) \cdot d\right)\right] \cdot 2,}
\end{aligned}
$$



variable shearing area

where: $d$-sample diameter, $\mathrm{mm} ; \boldsymbol{u}$-horizontal displacement, mm.

Peak shearing strength is obtained according to $\tau / \sigma_{n}=\max$. Residual shearing strength is obtained evaluating results from peak shearing strength till the end of testing procedure according to $\tau / \sigma_{n}=\min$. Normally lowest tangential and vertical stress ratio is obtained, when horizontal displacement is around $9.00 \mathrm{~mm}$ (Thiel 2001). For vertical and tangential force measurements it was used $S$ - type full bridge load transducers (Lamande $e t$ al. 2015).

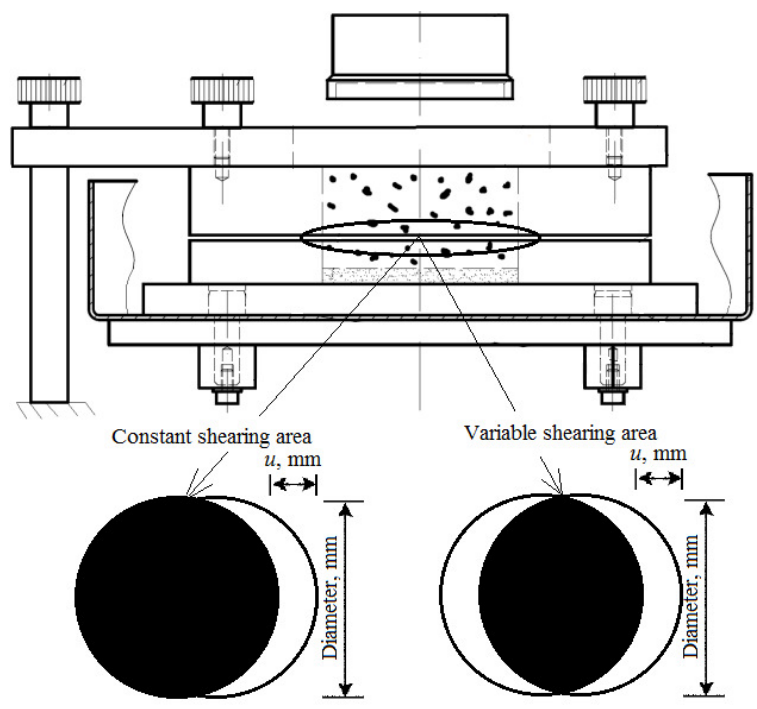

Fig. 2. Graphical explanation of constant and variable shearing area

\section{Analysis of obtained results}

As it was mentioned above, all direct shear tests was accomplished according to two different shearing methodologies. First of all, it is presented normal vertical stress and tangential stress analysis under peak and residual shearing strength (Table 1). Purpose of this comparison reveal the difference of normal vertical stresses and tangential stresses, when testing procedure is accomplished according to variable shearing area. For this reason, calculated normal stresses and tangential stresses, according to constant shearing area is having lower stresses values in comparison with obtained according to variable shearing area.

Analysis of peak shearing strength normal stresses obtained according to constant and variable shearing area on average differs $11.41 \%$. The same difference obtained for tangential stresses under peak shear strength comparison. Comparing residual shearing strength stresses - difference between constant and variable shearing area normal stresses on average is $18.37 \%$ and $18.58 \%$ for tangential stresses.

Obtained normal and tangential stresses differences at the peak shearing strength is not so big (11.41\%) that could make a very huge influence for soil testing results. Peak shearing strength angle of internal friction obtained according to constant shearing area is $\varphi=28.75^{\circ}$ and according to variable shearing area $\varphi=28.77^{\circ}$. This fact allows to run direct shear test without direct evaluation of variable shearing area during test procedure.

Table 1. Peak and residual shearing strength analysis according to constant and variable shearing area

\begin{tabular}{|c|c|c|c|c|c|c|c|c|c|c|c|}
\hline \multicolumn{6}{|c|}{ Peak shearing strength } & \multicolumn{6}{|c|}{ Residual shearing strength } \\
\hline \multicolumn{2}{|c|}{ Constant shearing area } & \multicolumn{2}{|c|}{ Variable shearing area } & \multicolumn{2}{|c|}{ Difference, $\%$} & \multicolumn{2}{|c|}{ Constant shearing area } & \multicolumn{2}{|c|}{ Variable shearing area } & \multicolumn{2}{|c|}{ Difference, $\%$} \\
\hline$\sigma_{n}, \mathrm{kPa}$ & $\tau, \mathrm{kPa}$ & $\sigma_{n}, \mathrm{kPa}$ & $\tau, \mathrm{kPa}$ & $\Delta \sigma_{n}$ & $\Delta \tau$ & $\sigma_{n}, \mathrm{kPa}$ & $\tau, \mathrm{kPa}$ & $\sigma_{n}, \mathrm{kPa}$ & $\tau, \mathrm{kPa}$ & $\Delta \sigma_{n}$ & $\Delta \tau$ \\
\hline 89.90 & 54.94 & 100.14 & 61.20 & 11.39 & 11.39 & 87.87 & 47.26 & 102.59 & 55.18 & 16.75 & 16.76 \\
\hline 90.98 & 54.48 & 100.77 & 60.34 & 10.76 & 10.76 & 89.23 & 46.19 & 104.69 & 54.20 & 17.33 & 17.34 \\
\hline 84.96 & 62.59 & 92.18 & 67.91 & 8.50 & 8.50 & 87.21 & 43.84 & 104.27 & 54.00 & 19.56 & 23.18 \\
\hline 82.50 & 47.74 & 97.79 & 56.58 & 18.53 & 18.52 & 85.36 & 48.80 & 101.25 & 57.89 & 18.62 & 18.63 \\
\hline 86.21 & 46.41 & 99.93 & 53.80 & 15.91 & 15.92 & 83.65 & 37.23 & 99.33 & 44.21 & 18.74 & 18.75 \\
\hline 89.57 & 58.54 & 99.38 & 64.95 & 10.95 & 10.95 & 89.96 & 49.50 & 106.74 & 58.74 & 18.65 & 18.67 \\
\hline 181.16 & 95.69 & 199.75 & 105.51 & 10.26 & 10.26 & 169.27 & 81.30 & 200.80 & 96.44 & 18.63 & 18.62 \\
\hline 184.54 & 121.39 & 200.55 & 131.93 & 8.68 & 8.68 & 168.75 & 101.69 & 200.24 & 120.67 & 18.66 & 18.66 \\
\hline 181.22 & 103.54 & 199.84 & 114.17 & 10.27 & 10.27 & 168.06 & 85.88 & 199.39 & 101.90 & 18.64 & 18.65 \\
\hline 181.62 & 98.69 & 200.46 & 108.93 & 10.37 & 10.38 & 169.27 & 84.52 & 200.81 & 100.27 & 18.63 & 18.63 \\
\hline 182.37 & 99.69 & 199.86 & 109.25 & 9.59 & 9.59 & 168.12 & 84.81 & 199.42 & 100.60 & 18.62 & 18.62 \\
\hline 181.86 & 106.08 & 199.69 & 116.48 & 9.80 & 9.80 & 168.55 & 86.75 & 199.82 & 102.84 & 18.55 & 18.55 \\
\hline 271.39 & 167.03 & 300.21 & 184.77 & 10.62 & 10.62 & 253.34 & 141.96 & 300.11 & 168.17 & 18.46 & 18.46 \\
\hline 268.96 & 152.06 & 299.85 & 169.52 & 11.48 & 11.48 & 252.48 & 132.25 & 299.42 & 156.83 & 18.59 & 18.59 \\
\hline 264.84 & 168.34 & 300.50 & 191.01 & 13.46 & 13.47 & 254.05 & 155.20 & 300.64 & 183.67 & 18.34 & 18.34 \\
\hline 270.19 & 142.38 & 299.80 & 157.99 & 10.96 & 10.96 & 254.86 & 127.84 & 300.51 & 150.74 & 17.91 & 17.91 \\
\hline 270.12 & 146.79 & 300.62 & 163.37 & 11.29 & 11.30 & 256.47 & 129.69 & 301.14 & 152.28 & 17.42 & 17.42 \\
\hline 266.77 & 145.53 & 300.12 & 163.73 & 12.50 & 12.51 & 252.63 & 110.01 & 299.57 & 130.45 & 18.58 & 18.58 \\
\hline
\end{tabular}



variable shearing area

Examining residual shearing strength obtained angle of internal friction according to constant shearing area is $\varphi=27.66^{\circ}$ and according to variable shearing area $\varphi=27.61^{\circ}$. In this case even almost $20 \%$ difference of normal and tangential stresses difference obtained by constant and variable shearing areas is not having influence for shearing strength results.

In both cases, when it is analysed peak and residual shearing strength obtained difference of angle of internal friction according to constant and variable shearing varies from $0.02^{\circ}$ to $0.05^{\circ}$. Variety appears, because angle of internal friction changes (Bareither et al. 2008) according to used low and/or high normal vertical stress during testing procedure (Huang et al. 2015; Senatore, Iagnemma 2011; Kang 2014; Kang et al. 2015).

Detailed peak shearing strength comparison according to constant and variable shearing area is given in Figure 3. Residual shearing strength comparison with two different shearing parameters evaluation methodologies is given Figure 4.

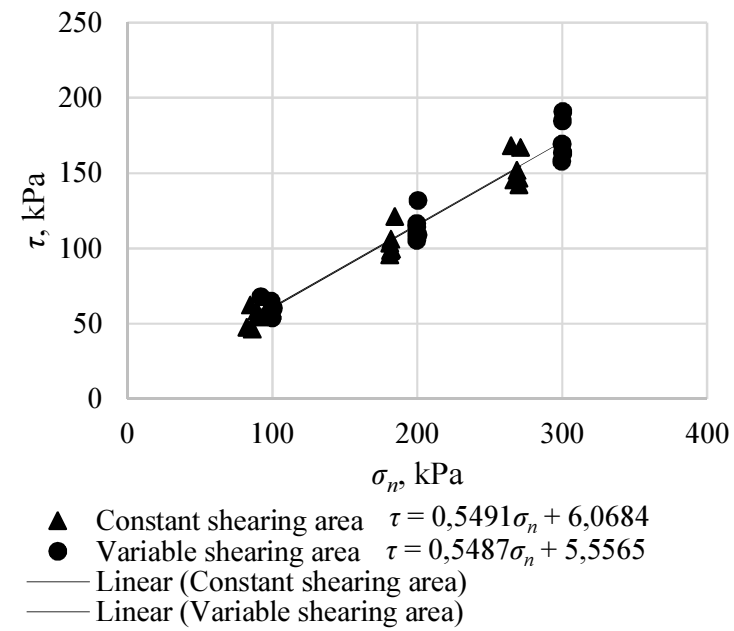

Fig. 3. Peak shearing strength comparison according to constant and variable shearing area

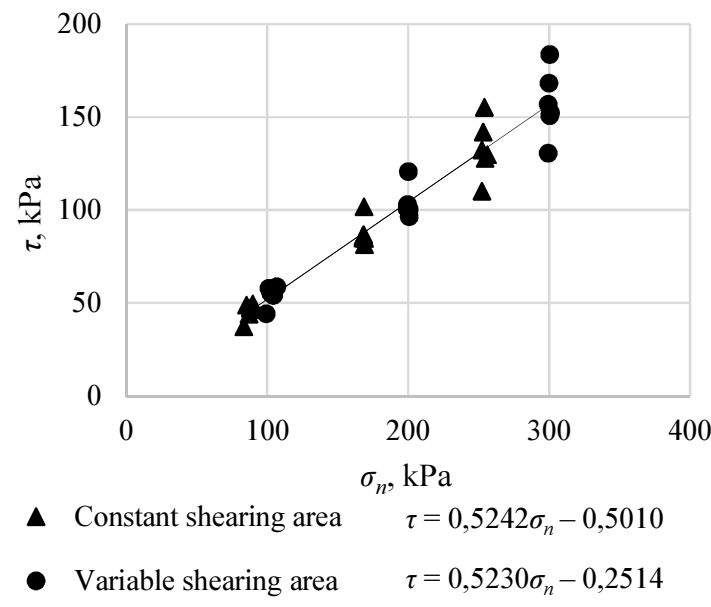

Fig. 4. Residual shearing strength comparison according to constant and variable shearing area

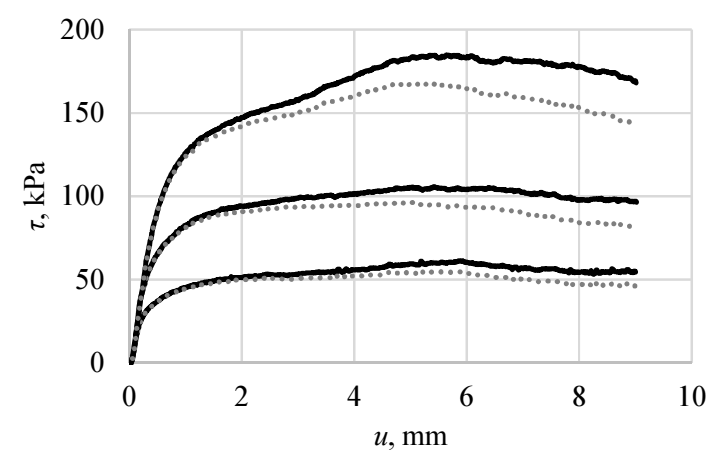

Fig. 5. Tangential stress versus horizontal displacement: continuos line - variable shearing area; dot line - constant shearing area

Direct shear tests results given in Figures 3 and 4 once again showing, that angle of internal friction is practically the same if it is compared constant and variable shearing area testing methodologies. Nevertheless, in both figures (Figs 3-4) it is clearly seen normal and tangential stresses differences of two different testing methodologies, especially stresses differences increases, when analyzing residual shearing strength (Fig. 4).

As an example on stresses differences it is presented tangential stress path diagram according to horizontal displacement testing the same soil with constant normal vertical stress $\sigma_{n}=100 ; 200$ and $300 \mathrm{kPa}$ (Fig. 5).

In Figure 5 given tangential stresses differences clearly shows, that these differences increases according to horizontal displacement increment and normal vertical stress value - at big displacements and higher normal vertical stresses tangential stresses difference are bigger $(\sim 20 \%)$.

\section{Conclusions}

A series of direct shear tests were conducted for normal and tangential stresses evaluation according to constant and variable shearing area. Analysis of stresses differences provided at the peak and residual shearing strength. Following findings were drawn from this study:

1) Normal and tangential stress at the peak shearing strength according to variable shearing area is $11.41 \%$ higher than comparing with obtained according to constant shearing area;

2) Normal and tangential stress at the residual shearing strength according to variable shearing area is $\sim 18.5 \%$ higher than comparing with obtained according to constant shearing area;

3) Implementation of variable shearing area into direct shear test procedure does not have any influence for angle of internal friction. Variable shearing area helps only to evaluate more accurate normal and tangential stresses;

4) All these conclusions can be applied only for direct shear tests provided with controlled vertical stress. Small difference of stresses comparison can appear, because not for all sands peak and residual shearing strength is obtained at the same horizontal displacement. 

variable shearing area

For tests conducted according to constant volume it is necessary to provide another research study.

\section{Acknowledgements}

An equipment and infrastructure of Civil Engineering Research Centre of Vilnius Gediminas Technical University was employed.

\section{References}

Bareither, C. A.; Edil, T. B.; Benson, C. H.; Mickelson, D. B. 2008. Geological and physical factors affecting the friction angle of compacted soils, Journal of Geotechnical and Geoenvironmental Engineering 134(10): 1476-1489. http://dx.doi.org/10.1061/(ASCE)1090-0241(2008)134: 10(1476)

Havaee, S.; Mosaddeghi, M. R.; Ayoubi, S. 2015. In situ surface shear strength as affected by soil characteristics and land use in calcareous soils of central Iran, Geoderma 237238(2015): 137-148. http://dx.doi.org/10.1016/j.geoderma.2014.08.016

Huang, W. C.; Sung, C. Y.; Liao, H. Y.; Chu, S. S. 2015. Micromechanical behaviour of granular materials in direct shear modeling, Journal of the Chinese Institute of Engineers 38(4): 469-480. http://dx.doi.org/10.1080/02533839.2014.998286

Kang, J. H. 2014. Exact solutions of stresses, strains, and displacements of a perforated rectangular plate by central circular hole subjected to linearly varying in-plane normal stresses on two opposite edges, International Journal of Mechanical Sciences 84: 18-24. http://dx.doi.org/10.1016/j.ijmecsci.2014.03.023

Kang, X.; Cheng, Y.; Ge, L. 2015. Radial strain behaviours and stress state interpretation of soil under direct simple shear, Journal of Testing and Evaluation 4396: 1-8. http://dx.doi.org/10.1520/JTE20140202

Khalilmoghadam, B.; Afyuni, M.; Abbaspour, K. C.; Jalalian, A.; Dehghani, A. A.; Schulin, R. 2009. Estimation of surface shear strength in Zagros region of Iran - a comparison of artificial neural networks and multiple-linear regression models, Geoderma 153: 29-36. http://dx.doi.org/10.1016/j.geoderma.2009.07.008

Kimura, S.; Nakamura, S.; Vithana, S. B. 2015. Influence of effective normal stress in the measurment of fully softened strength in different origin landslide soils, Soil \& Tillage Research 145: 47-54. http://dx.doi.org/10.1016/j.still.2014.07.018
Lane, J. J.; Vanapalli, S. K. 2002. A Simple technique for determining the shear strength of fine-grained unsaturated soils using the conventional direct shear apparatus, in $2^{\text {nd }}$ Canadian Specialty Conference on Computer Applications in Geotechnique, 28-30 April 2002, Winnipeg, Canada, 245-253.

Lamande, M.; Keller, T.; Berisso, F.; Stettler, M. 2015. Accuracy of soil stress measurments as affected by transducer dimensions and shape, Soil \& Tillage Research 145: 7277. http://dx.doi.org/10.1016/j.still.2014.08.011

Naranjo, S. D.; Sandu, C.; Taheri, S.; Taheri, Sh. 2014. Experimental testing of an off-road instrumented tire on soft soil, Journal of Terramechanics 56: 119-137. http://dx.doi.org/10.1016/j.jterra.2014.09.003

Nguyen, G. 2015. Consideration of speciments shear area changes during direct shear test of soils and its effects on a size of spread foundation, in International Multidisciplinary Scientific GeoConference SGEM: Surveying Geology \& mining Ecology Management, 18-24 June 2015, Surveying Geology \& Mining Ecology Management (SGEM), Sofia, 2: 203-208.

Senatore, C.; Iagnemma, K. D. 2011. Direct shear behaviour of dry, granular soils for low normal stress with application to lightweight robotic vehicle modelling, in Proceedings of the $17^{\text {th }}$ International Conference, 18-22 September 2011, Blacksburg, VA, USA.

Skuodis, Š. 2015. Experimental and numerical investigations of sand morphological parameters influence on soil mechanical properties: $\mathrm{PhD}$ thesis. Vilnius Gediminas Technical University (in Lithuanian).

Skuodis, Š.; Tamošiūnas, T. 2014. Direct shear tests with evaluation of variable shearing area, Science - Future of Lithuania 6(5): 499-503. http://dx.doi.org/10.3846/mla.2014.692

Taheri, S.; Sandu, C.; Taheri, S.; Pinto, E.; Gorsich, D. 2015. A technical survey on Terramechanics models for tire-terrain interaction used in modeling and simulation of wheeled vehicles, Journal of Terramechanics 57: 1-22. http://dx.doi.org/10.1016/j.jterra.2014.08.003

Takano, D.; Chevalier, B.; Otani, J. 2014. Experimental and numerical simulation of shear behaviour on sand and tire chips, in $14^{\text {th }}$ IACMAG International Conference, September 2014, Kyoto, Japan.

Thiel, R. 2001. Peak vs. residual shear strength for bottom liner stability analyses, in Proceedings of the GRI-15 Conference, 12-14 December 2001, Houston, USA, 40-70.

Wang, J. J.; Zhang, H. P. Wen, H. B.; Liang, Y. 2015. Shear strength of an accumulation soil from direct shear test, Marine Georesources \& Geotechnology 33(2): 183-190. http://dx.doi.org/10.1080/1064119X.2013.828821 